\title{
Model Predictive Control Method of hybrid Battery energy storage system for Smoothing Wind Power Fluctuation
}

\author{
Li Jianlin ${ }^{1}$, Tan Yuliang ${ }^{1}$ \\ ${ }^{1}$ Energy Storage Technology Engineering Research Center (North China University of Technology), Shijingshan District, Beijing \\ 100144, China
}

\begin{abstract}
In a large-scale wind power generation system, active power fluctuation caused by random wind speed will have a serious impact on the power grid. In order to limit the power fluctuation that wind farm transmits to the power grid and protect the energy storage battery, this paper has proposed a model predictive control method of hybrid energy storage by optimizing the objective function and constraint conditions. Firstly, the mathematical model of predictive control method has been established in a wind power system with hybrid energy storage. Then, with the goal of minimum energy storage output and maximum charging-discharging capacity of the super-capacitor, the predictive control process has been optimized. Meanwhile, the constraint on the output power of the battery has been dynamically changed to reduce its charging-discharging switching frequency, and the model predictive control strategy of the hybrid energy storage has been formed. Finally, compared with the model prediction control method of single energy storage, based on a wind farm data, the simulation results show that the proposed method can smooth wind power fluctuation, reduce the time that the power does not satisfy the fluctuation requirements, ensure the capability of the super-capacitor, and reduce the charging-discharging switching frequency of the energy storage battery.
\end{abstract}

\section{Introduction}

In the process that large-scale integrated wind farm transmits power to power grid, its volatility and randomness have a great impact on the safe operation and reliable control of power systems ${ }^{[1]}{ }^{[2]}$. As an effective way to smooth wind power fluctuations, energy storage is focused by more and more researchers and the research on control strategies for energy storage systems is particularly important ${ }^{[3]}$.

Experts and scholars have carried out a series of researches on control methods for smoothing wind power fluctuations using energy storage systems. For example, the literature [4] proposed a four-step coordinated control method based on adaptive linear neurons, using a charging state feedback control strategy to achieve reasonable constraints on grid-connected power fluctuations, and to ensure that the battery runs in a safe state. Based on the variable time constant low-pass filtering method of the energy storage energy state, literature [5] achieves the control effect of decomposing wind power into grid-connected power and energy storage tracking power. Considering the delay of low-pass filtering, literature[6] combined empirical mode decomposition with wavelet analysis to better analyze the characteristics of wind power and smooth the fluctuation of wind power. Literature [7-8] introduces fuzzy theory into the control process of smoothing power fluctuation, and adaptively obtained the grid-connected wind power and energy storage output power to avoid excessive charging and discharging of energy storage and prolong the energy storage life. With the development of wind speed, wind power prediction and optimization technology, researchers have found that the future output of wind power affects the current output power of energy storage. Therefore, energy storage control methods that take wind power prediction power changes into account attracts a lot of attention. Literature [9] established a rolling optimization model with multiple generator units and multiple prediction segments. This paper has made progress in overall optimization levels and forward-looking scheduling decisions. Literature [10] applied the model predictive control method to the energy storage system to obtain the optimal control sequence for a period of time. The literature [11] input the future wind power fluctuations and the current energy storage energy state into the fuzzy controller, which rationally controlled the energy storage output and obtained good results.

In order to further improve the economics of wind and energy storage systems, many experts and scholars have analyzed the life problem of energy storage batteries and

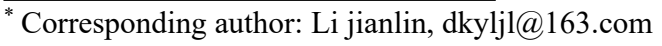


established reasonable using methods of energy storage to provide guidance for increasing their service life. Literature[12-13] respectively analyzed the impact of energy changes and discharge depths on the cycle life of lead-acid batteries and lithium iron phosphate batteries. Literature [14] and [15] introduced the rain-flow counting method into the energy storage battery output loss, an operational damage model for energy storage batteries was established to effectively evaluate the cycle life of energy storage batteries. Literature [16]-[17] designed a double-battery energy storage system, which put the two groups of batteries in different charge and discharge states, and stabilized the positive and negative fluctuation components of wind power alternately to obtain a good control effect. On the basis of this idea, the literature [18] combined with the model predictive control idea, while smoothing the wind power fluctuation, greatly reducing the charge-discharge switching frequency of the energy storage battery, and verified the superiority of the proposed method from the perspective of economic cost. With the development of power type energy storage such as super-capacitors and flywheel energy storage, the characteristics of high power density and high cycle life have been widely valued. The control of hybrid energy storage systems including energy storage batteries and super-capacitors or flywheel energy storage has become a research hotspot. Literature [19] used batteries to compensate for low-frequency fluctuations of wind power, while super-capacitors were used to compensate for high-frequency power fluctuations, reducing the frequency of charging and discharging energy storage batteries. the literature [20-22] according to the empirical model decomposition and its improved set of empirical modal decomposition and variational model decomposition, using the energy storage energy state to adaptively constrain the battery and super-capacitor power instructions. While meeting the grid-connected power fluctuation requirements, at the same time the energy storage charge state is maintained within a reasonable range. Literature [23] used the model predictive control theory to obtain the total energy storage load of the energy storage system with smooth wind power, and based on the characteristics of the battery and super-capacitor, the first-order low-pass filter cutoff frequency was designed using the Hilbert-Huang Transform. Effective distribution of energy storage power is achieved.

In the study of smoothing wind power fluctuations, many literatures have proposed a number of energy storage battery and hybrid energy storage coordinated control methods, however the discussion about the frequent charge and discharge constraints of energy storage batteries and the optimization of super-capacitor capabilities are less. Therefore, this paper proposes a model predictive control method that uses hybrid energy storage to smooth wind power fluctuations. First, based on the wind-grid-storage power relationship, a mathematical model for predictive control of a hybrid energy storage system is established. Then, a model predictive control strategy is designed with the minimum energy storage output and the maximum super-capacitor output. Based on the energy state of the energy storage battery, the output power constraints are dynamically updated to reduce the frequency of charge and discharge switching of the energy storage battery. Finally, based on the data of a wind farm, the effect, economy and parameters of model predicted control in the single and hybrid energy storage. The superiority of the proposed method is also verified.

\section{Wind power generation system with double energy storagel}

\subsection{Hybrid energy storage and wind power system structure and power relationship}

Uncertain changes of wind speed cause active power fluctuations in wind power. When a single energy storage battery smooths the fluctuations of wind power, charge-discharge switching is frequent, which greatly damages its service life. In order to improve the economy of energy storage batteries, meet the requirements of grid-connected power fluctuations and protect the life of energy storage batteries at the same time, a double energy storage model predictive control strategy is proposed in this paper to stabilize wind power fluctuations. The energy storage battery maintains low-frequency, low-power charging and discharging operation. The super capacitor is responsible for high-frequency, high-power charging and discharging operation. The structure and the energy flow direction of the hybrid energy storage and wind power generation system are shown in Figure 1. The relationship can be expressed as follows:

$$
\begin{array}{r}
P_{\mathrm{g}}(k+1)=P_{\mathrm{b}}(k)+P_{\mathrm{c}}(k)+P_{\mathrm{w}}(k) \\
C_{\mathrm{SOEb}}(k+1)=C_{\mathrm{SOEb}}(k)-P_{\mathrm{b}}(k) \times T_{\mathrm{c}} / Q_{\mathrm{be}} \\
C_{\mathrm{SOEc}}(k+1)=C_{\mathrm{SOEc}}(k)-P_{\mathrm{c}}(k) \times T_{\mathrm{c}} / Q_{\mathrm{ce}}
\end{array}
$$

$\mathrm{P}_{\mathrm{g}}(\mathrm{k}+1)$ represents the grid-connected power at $\mathrm{k}+$ $1, \mathrm{P}_{\mathrm{w}}(\mathrm{k})$ represents the output power of the wind farm at $\mathrm{k}, \mathrm{P}_{\mathrm{b}}(\mathrm{k}), \mathrm{C}_{\mathrm{SOEb}}(\mathrm{k})$, and $\mathrm{Q}_{\mathrm{be}}$ respectively represent the output power, energy states and rated capacity of the energy storage battery, $\mathrm{P}_{\mathrm{c}}(\mathrm{k}), \mathrm{C}_{\mathrm{SOEc}}(\mathrm{k})$, and $\mathrm{Q}_{\mathrm{ce}}$ respectively represent the output power, energy state, and capacity of the super capacitor, $\mathrm{T}_{\mathrm{c}}$ represents the control period. 


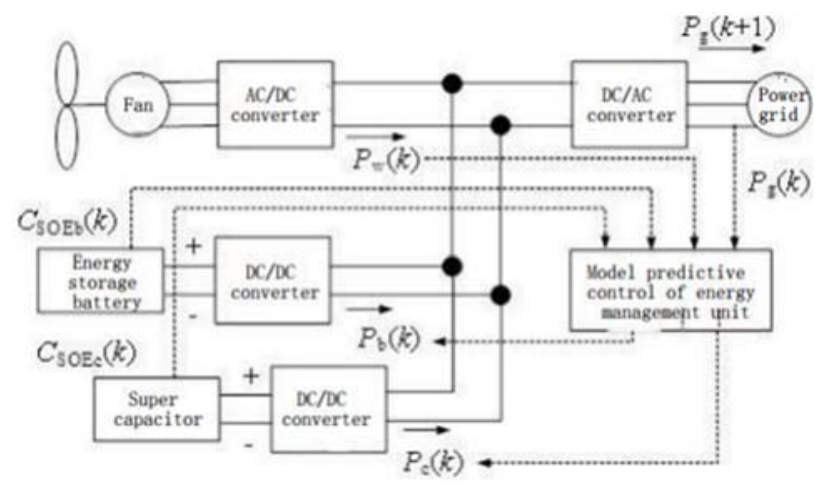

Fig.1 Structure and energy flow of wind power system with a hybrid energy storages

\subsection{Definition of Wind Power Smoothing Index}

The performance of the proposed hybrid and single energy storage model predictive control method is compared from two perspectives: grid-connected wind power fluctuations and SOE operating status of energy storage batteries [11].Define four indicators to evaluate the advantages and disadvantages of control strategy: $\Delta \mathrm{P}_{\mathrm{g} \text {, mean }}$ the average absolute value of the average power fluctuation,,$T_{d}$ the time that the grid-connected power does not meet the fluctuation requirements, $\mathrm{E}_{\mathrm{b}}$ the total charge and discharge energy of the energy storage battery during operation, and $\mathrm{N}_{\mathrm{cd}}$ the number of charge and discharge switches of the energy storage battery. Four indicators are shown in equations (4) (11).

1) Average of absolute value of grid-connected power fluctuation

$$
\begin{aligned}
\Delta P_{\mathrm{g}}(k)=\mid P_{\mathrm{g}}(k+1)- & P_{\mathrm{g}}(k) \mid \\
\Delta P_{\mathrm{g}, \text { mean }} & =\frac{1}{N-1} \sum_{k=0}^{N-1} \Delta P_{\mathrm{g}}(k)
\end{aligned}
$$

$\Delta \mathrm{P}_{\mathrm{g}}(\mathrm{k})$ is the absolute value of grid-connected power fluctuation at time $\mathrm{k}$, and $\Delta \mathrm{P}_{\mathrm{g}}$, mean is the absolute value of grid-connected power fluctuation, which indicates the smoothing wind power level of the energy storage battery.

2) The time that grid-connected power does not meet fluctuation requirements

$$
\begin{array}{r}
T_{\mathrm{d}}=T_{\mathrm{c}} \times \sum_{k=0}^{N-1} h\left(P_{g}(k)\right) \\
h\left(P_{g}(k)\right)= \begin{cases}1 & \left|P_{g}(k)-P_{g}(k-1)\right| \geq \delta \\
0 & \left|P_{g}(k)-P_{g}(k-1)\right|<\delta\end{cases}
\end{array}
$$

$\mathrm{T}_{\mathrm{d}}$ is the time that the grid-connected power does not meet the grid power fluctuation $\delta$, which means that the grid-connected wind power will have an inestimable impact on the grid. If $\mathrm{T}_{\mathrm{d}}$ is too large, the wind power output will be limited to reduce the impact on the grid.
3 ) Total energy of charge and discharge during storage battery operation

$$
E_{\mathrm{b}}=\sum_{k=0}^{N-1}\left|P_{\mathrm{b}}(k)\right| T_{c}
$$

$E_{b}$ is the total energy stored in charging and discharging during smoothing wind power fluctuations, which indicates the output of the energy storage battery during operation. The smaller the value, the less the energy storage output power, which is beneficial to prolong the life of the energy storage battery.

4 ) Charge and discharge switch times of energy storage battery

$$
\begin{array}{r}
N_{\text {cd }}=\sum_{k=1}^{T-1} S(k) \\
A(k)=\left\{\begin{array}{ccc}
P(k-1) & \text { if } & P(k)=0 \\
P(k) & \text { if } & P(k) \neq 0
\end{array}\right.
\end{array}
$$

$S(k)=\left\{\begin{array}{lll}0 & \text { if } & P(k) \times P(k+1) \geq 0 \\ 1 & \text { if } & P(k) \times P(k+1)<0\end{array}\right.$

$\mathrm{N}_{\mathrm{cd}}$ is the number of times the energy storage battery is charged and discharged during the fluctuation of wind power, which indicates the change in the state of charge and discharge of the energy storage battery. The smaller the value, the better the life protection of the energy storage battery.

\section{Predictive control strategies for hybrid energy storage models}

\subsection{Mathematical model and calculation of hybrid energy storage to smooth wind power fluctuation}

Model predictive control adopts the concepts of rolling prediction and advance control, and considers the impact of current energy storage output on its future output capacity [19-21]. This paper designs a model predictive control process for smoothing wind power fluctuations in hybrid energy storage batteries. According to the power relation formulas $(1) \sim(3)$ of the hybrid energy storage and wind power generation system, this paper assumes the state variable $\mathrm{x}=(\mathrm{x} 1, \mathrm{x} 2, \mathrm{x} 3)$, the control variable $\mathrm{u}$ $=(\mathrm{u} 1, \mathrm{u} 2)$, and the input variable $\mathrm{r}$, where $x_{1}(k)=P_{\mathrm{g}}(k)$, $x_{2}(k)=C_{\mathrm{SOEb}}(k), x_{3}(k)=C_{\mathrm{SOEc}}(k), u_{1}(k)=P_{\mathrm{b}}(k), u_{2}(k)=P_{\mathrm{c}}(k)$ and $r(k)=P_{\mathrm{w}}(k)$. Then the state space equation of the double energy storage wind power system is

$$
\begin{aligned}
& \boldsymbol{x}(k+1)=\boldsymbol{A} \boldsymbol{x}(k)+\boldsymbol{B}_{1} u(k)+\boldsymbol{B}_{2} r(k) \\
& \boldsymbol{A}=\left[\begin{array}{lll}
0 & 0 & 0 \\
0 & 1 & 0 \\
0 & 0 & 1
\end{array}\right] \boldsymbol{B}_{1}=\left[\begin{array}{cc}
1 & 1 \\
-T_{\mathrm{c}} / Q_{\mathrm{be}} & 0 \\
0 & -T_{\mathrm{c}} / Q_{\mathrm{ce}}
\end{array}\right] \boldsymbol{B}_{2}=\left[\begin{array}{l}
1 \\
0 \\
0
\end{array}\right]
\end{aligned}
$$

Different from the traditional objective function that only uses the minimum energy storage output as the 
optimized objective, this paper takes into account the minimum output of energy storage batteries and super capacitors, and considers the situation of small super capacitors and high capacity costs. The discharge capacity is also used as part of the optimization function to calculate the control process, in order to prevent the super capacitor reaching the charge / discharge limit and cannot charge and discharge in the way of high frequency and low power. The hybrid optimization objective function defined in in each optimization period is shown in formula (13).

$$
J=\sum_{i=0}^{M-1}\left\{\left(\frac{P_{\mathrm{b}}(k+i)}{P_{\mathrm{be}}}\right)^{2}+\left(\frac{P_{\mathrm{c}}(k+i)}{P_{\mathrm{ce}}}\right)^{2}+\left(C_{\mathrm{SOEc}}(k+i)-C_{\mathrm{SOE}, \operatorname{mid}}\right)^{2}\right\}
$$

$\mathrm{P}_{\mathrm{be}}$ and $\mathrm{P}_{\mathrm{ce}}$ respectively indicate the rated power of the energy storage battery and the super capacitor, and $\mathrm{C}_{\mathrm{SOEc}}(\mathrm{k}+\mathrm{i})$ represents the energy state of the super capacitor at time $\mathrm{k}+\mathrm{i}$, and its range is $[0,1]$, and $\mathrm{C}_{\mathrm{SOEc}}$, mid is The energy state of the super capacitor at its maximum charge and discharge capacity, that is, $\mathrm{C}_{\mathrm{SOEc}}$, mid $=0.5$. In order to standardize multiple optimization objective function values, the output power of the energy storage battery and super capacitor needs to be divided by their respective rated power.

In the process of optimizing energy storage and smooth wind power, it is also necessary to meet constraints such as grid-connected power fluctuation limits, energy storage power, and energy storage state, as shown in formulas (14) to (18).

$$
\begin{array}{r}
\left|P_{\mathrm{g}}(k+i+1)-P_{\mathrm{g}}(k+i)\right| \leq \delta, i=0,1, \ldots, M-1 \\
P_{\mathrm{bd}} \leq P_{\mathrm{b}}(k+i) \leq P_{\mathrm{bu}}, i=0,1, \ldots, M-1 \\
P_{\mathrm{cd}} \leq P_{\mathrm{c}}(k+i) \leq P_{\mathrm{cu}}, i=0,1, \ldots, M-1 \\
C_{\mathrm{SOEb}, \text { min }} \leq C_{\mathrm{SOEb}}(k+i) \leq C_{\mathrm{SOEb}, \max }, i=1, \ldots, M \\
C_{\mathrm{SOEc}, \text { min }} \leq C_{\mathrm{SOEc}}(k+i) \leq C_{\mathrm{SOEc}, \max }, i=1, \ldots, M
\end{array}
$$

$\delta$ represents the power range of grid-connected power fluctuations, $\mathrm{P}_{\mathrm{bu}}, \mathrm{P}_{\mathrm{bd}}, \mathrm{C}_{\mathrm{SOEb}}$. min, and $\mathrm{C}_{\mathrm{SOEb} \text { min }}$ respectively represent the upper and lower limits of the output power of the energy storage battery and the upper and lower limits of the energy state, and $\mathrm{P}_{\mathrm{cu}}, \mathrm{P}_{\mathrm{cd}}, \mathrm{C}_{\mathrm{SOEc}}$ min and $\mathrm{C}_{\mathrm{SOE} \text {.min }}$ represent the upper and lower limits of the output power of the supercapacitor and the upper and lower limits of the energy state, respectively. Generally, the upper and lower limits of the output power of energy storage batteries and supercapacitors are positive and negative rated power, that is, $\pm \mathrm{P}_{\text {be }}$ and $\pm \mathrm{P}_{\text {ce }}$. The upper and lower limits of the energy state of the battery energy are 0.8 and 0.2 , respectively. The upper and lower limits of the energy state of the super capacitor are 0.9 and 0.1 , respectively.

Based on the above objective function and constraint analysis, the mathematical model of the energy storage model predictive control at time $\mathrm{k}$ can be established as

$$
\begin{aligned}
& \min \frac{1}{2} z^{\mathrm{T}}\left[\begin{array}{lllll}
\boldsymbol{R} & 0 & 0 & 0 & 0 \\
0 & \boldsymbol{Q} & 0 & 0 & 0 \\
0 & 0 & \ddots & 0 & 0 \\
0 & 0 & 0 & \boldsymbol{R} & 0 \\
0 & 0 & 0 & 0 & \boldsymbol{Q}
\end{array}\right] z+\left[\begin{array}{c}
\boldsymbol{g} \\
\boldsymbol{f} \\
\boldsymbol{M} \\
\boldsymbol{g} \\
\boldsymbol{f}
\end{array}\right] \\
& \left\{\text { s.t. }\left[\begin{array}{cccccc}
\boldsymbol{B}_{1} & -\boldsymbol{I} & 0 & 0 & 0 & 0 \\
0 & \boldsymbol{A} & \boldsymbol{B}_{1} & -\boldsymbol{I} & 0 & 0 \\
0 & 0 & \ddots & \ddots & \ddots & 0 \\
0 & 0 & 0 & \boldsymbol{A} & \boldsymbol{B}_{1} & -\boldsymbol{I}
\end{array}\right] \boldsymbol{z}=\left[\begin{array}{c}
-\boldsymbol{A x}^{\mathrm{T}}(k)-\boldsymbol{B}_{2} r(k) \\
-\boldsymbol{B}_{2} r(k+1) \\
\cdots \\
-\boldsymbol{B}_{2} r(k+M-1)
\end{array}\right]\right. \\
& {\left[\begin{array}{ccccc}
\boldsymbol{A}_{\mathrm{s}} & 0 & 0 & 0 & 0 \\
\boldsymbol{a}_{\mathrm{s}} & \boldsymbol{A}_{\mathrm{s}} & 0 & 0 & 0 \\
0 & \ddots & \ddots & 0 & 0 \\
0 & 0 & \boldsymbol{a}_{\mathrm{s}} & \boldsymbol{A}_{\mathrm{s}} & 0 \\
0 & 0 & 0 & \boldsymbol{a}_{\mathrm{q}} & \boldsymbol{A}_{\mathrm{q}}
\end{array}\right] \boldsymbol{z} \leq\left[\begin{array}{c}
\boldsymbol{B}_{\mathrm{s}} \\
\boldsymbol{B}_{\mathrm{s}} \\
\vdots \\
\boldsymbol{B}_{\mathrm{s}} \\
\boldsymbol{B}_{\mathrm{q}}
\end{array}\right]}
\end{aligned}
$$

$\mathrm{z}=[\mathrm{u}(\mathrm{k}), \mathrm{xT}(\mathrm{k}+1), \mathrm{u}(\mathrm{k}+1) \ldots, \mathrm{u}(\mathrm{k}+\mathrm{M}-1), \mathrm{xT}$ $(\mathrm{k}+\mathrm{M})] \mathrm{T}, \mathrm{H}$ is the matrix constituted by the quadratic term weights $\mathrm{R}$ and $\mathrm{Q}$ of the hybrid energy storage and super capacitor charge and discharge capacity respectively;

$\mathrm{F}$ is a row vector composed of the primary output weights $g$ and $f$ of the energy storage output power and the capacity of the super capacitor. According to the optimization objective formula (13), $\mathrm{R}=[1 /$ (Pbe) $20 ; 0$

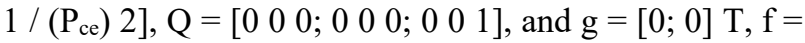
$[0,0,-0.5] \mathrm{T} ; \mathrm{As}, \mathrm{as}, \mathrm{A}_{\mathrm{q}}, \mathrm{a}_{\mathrm{q}}, \mathrm{B}_{\mathrm{s}}, \mathrm{B}_{\mathrm{q}}$ matrix can be obtained according to formulas (14) to (18).

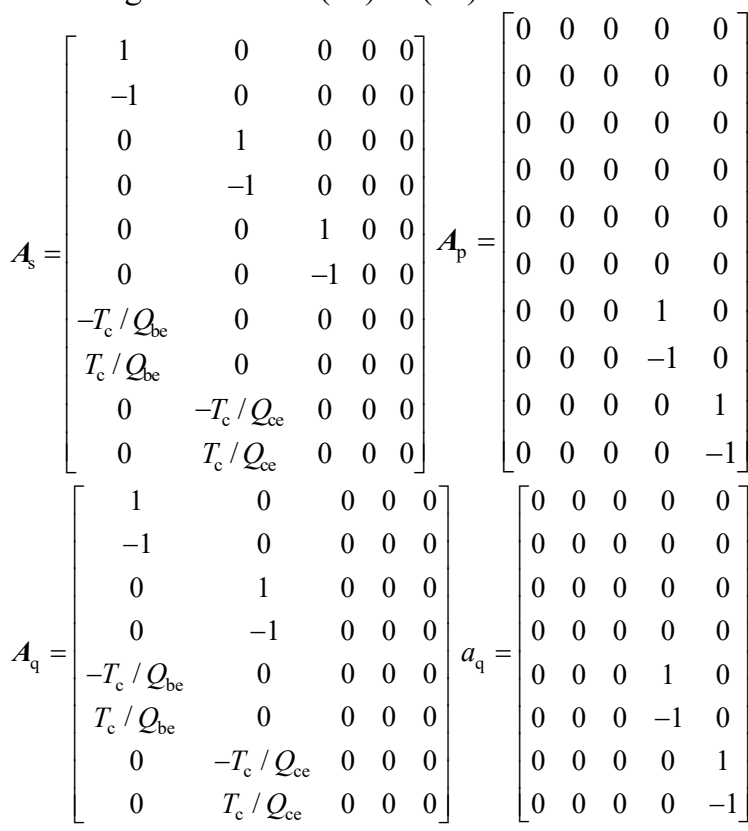

$\boldsymbol{B}_{\boldsymbol{s}}=\left[P_{b u},-P_{\mathrm{bd}}, P_{\mathrm{cu}},-P_{\mathrm{cd}}, \delta, \delta,-C_{\mathrm{SOEb}, \min }, C_{\mathrm{SOEb}, \max },-\right.$ $\left.C_{\mathrm{SOEc}, \min }, C_{\mathrm{SOEc}, \max }\right]^{\mathrm{T}}, \boldsymbol{B}_{\mathrm{q}}=\left[P_{\mathrm{bu}},-P_{\mathrm{bd}}, P_{\mathrm{cu}},-P_{\mathrm{cd}},-C_{\mathrm{SOEb}, \min }\right.$, $\left.C_{\text {SOEb,max }}, \quad-C_{\text {SOEc,min }}, C_{\text {SOEc,max }}\right]^{\mathrm{T}}$. The quadratic programming method is used to solve the model predictive control at time $\mathrm{k}$ represented by formula (19). The obtained variable $\mathrm{z}$ contains the control sequence for a period of time $[\mathrm{u}(\mathrm{k}), \mathrm{u}(\mathrm{k}+1), \ldots, \mathrm{u}(\mathrm{k}+\mathrm{M}-1)]$, take $\mathrm{u}$ (k) as the hybrid energy storage output power $\mathrm{Pb}(\mathrm{k}), \mathrm{Pc}$ (k) at time $\mathrm{k}$, update the grid-connected power and energy storage energy status, and scroll to the next time to repeat the above solution process. 


\subsection{Predictive control strategies for hybrid energy storage}

From the predictive control mathematical model of the hybrid energy storage established in Section 2.1, it can be seen that the objective function formula (13) reduces the energy storage output power while considering the problem of small super-capacitor capacity, introduces the super-capacitor charge and discharge capacity link and enhances super capacitor's ability to smooth wind power. However, frequent charging and discharging of energy storage batteries will lead to a reduction in the service life and affect the economics of energy storage system applications. However, it can be seen from the constraints that formula (15) can limit the range and plus or minus of the output power of the energy storage battery that is charging or discharging behavior. Formula (17) limits the energy state range of the energy storage battery, which can prevent the battery from impact on its life caused by excessive charge and discharge. Therefore, in this paper, based on the constraints, according to the range of battery energy status, the output power limit of the energy storage battery during the rolling prediction optimization process is changed to form a hybrid energy storage model predictive control strategy that reduces the frequency of charge and discharge of the energy storage battery.

The specific process is as follows, and the flowchart is shown in Fig. 2.

Step 1: Establish a mathematical model of the wind and hybrid energy storage generation system. Design a wind power prediction model based on the historical wind power data of the wind farm. Initialize the relevant parameter settings, and Flag $=0$.

Step 2: Update the wind power $\mathrm{P}_{\mathrm{W}}(\mathrm{k})$ and hybrid energy storage energy states $\mathrm{C}_{\mathrm{SOEb}}(\mathrm{k})$ and $\mathrm{C}_{\mathrm{SOEc}}(\mathrm{k})$ at time $\mathrm{k}$, and calculate $\mathrm{k}+1, \mathrm{k}+2, \ldots, \mathrm{k}+\mathrm{M}$ based on the historical wind power data and prediction model, then go to Step 3.
Step 3: Determine whether the energy state $\mathrm{C}_{\text {SOEb }}(\mathrm{k})$ of the energy storage battery at the current $\mathrm{k}$ reaches its lower discharge limit $\mathrm{C}_{\mathrm{SOEb} \text {,min. }}$. If yes, set the output power range of the energy storage battery to be $\left[-\mathrm{P}_{\mathrm{be}}, 0\right]$ respectively, and go to Step 5. If not, go to Step 4.

Step 4: Determine whether the current energy state $\mathrm{C}_{\text {SOEb }}(\mathrm{k})$ of the energy storage battery reaches its upper charging limit $\mathrm{C}_{\mathrm{SOEb}}$,max. If yes, the output power range of the energy storage battery is $\left[0, \mathrm{P}_{\mathrm{be}}\right]$, and proceed to Step 5. If not, the output power range of the energy storage battery is maintained at the output power range of the previous moment. The power range is $\left[-\mathrm{P}_{\mathrm{ce}}, \mathrm{P}_{\mathrm{ce}}\right]$, and go to Step 5.

Step 5: According to the objective function of formula (13) and the constraints of (14) to (18), establish a mathematical model of predictive control for the hybrid energy storage model of formula (19), and use the quadratic programming method to solve the model predictive control model to get the output sequence $\left[\mathbf{u}(k), \mathbf{x}^{\mathrm{T}}(k+1), \mathbf{u}(k+1) \ldots, \mathbf{u}(k+M-1), \mathbf{x}^{\mathrm{T}}(k+M)\right]^{\mathrm{T}}$. If the optimization sequence exists, let the output power of the energy storage battery in the hybrid energy storage at time $\mathrm{k} \quad \mathrm{P}_{\mathrm{b}}(\mathrm{k})=\mathrm{u}_{1}(\mathrm{k})$ and the output power of the super capacitor $\mathrm{Pc}(\mathrm{k})=\mathrm{u}_{2}(\mathrm{k})$, and go to Step 8. If yes, go to Step 6.

Step 6: Determine whether the upper limit value $P_{b u}$ (k) of the output power of the energy storage battery is equal to the rated power $\mathrm{P}_{\mathrm{be}}$ at $\mathrm{k}$. If yes, the battery output power range becomes $\left[-\mathrm{P}_{\mathrm{be}}, 0\right]$. If not, becomes $[0$, $\left.\mathrm{P}_{\mathrm{be}}\right]$, and the flag bit Flag $=$ Flag +1 , and go to Step 7 .

Step 7: Determine whether the flag bit is equal to 1. If it is, return to Step 5. If it is not, make the output power of the energy storage battery $\mathrm{P}_{\mathrm{b}}(\mathrm{k})=0$ and the output power of the super capacitor $P_{c}(k)=0$. Then go to Step 8.

Step 8: Determine whether $\mathrm{k}$ is less than the time $\mathrm{k}_{\text {end }}$ that the hybrid energy storage smooth wind power. If yes, the process ends. If not, let $\mathrm{k}=\mathrm{k}+1$ and Flag $=0$, then return to Step 2. 


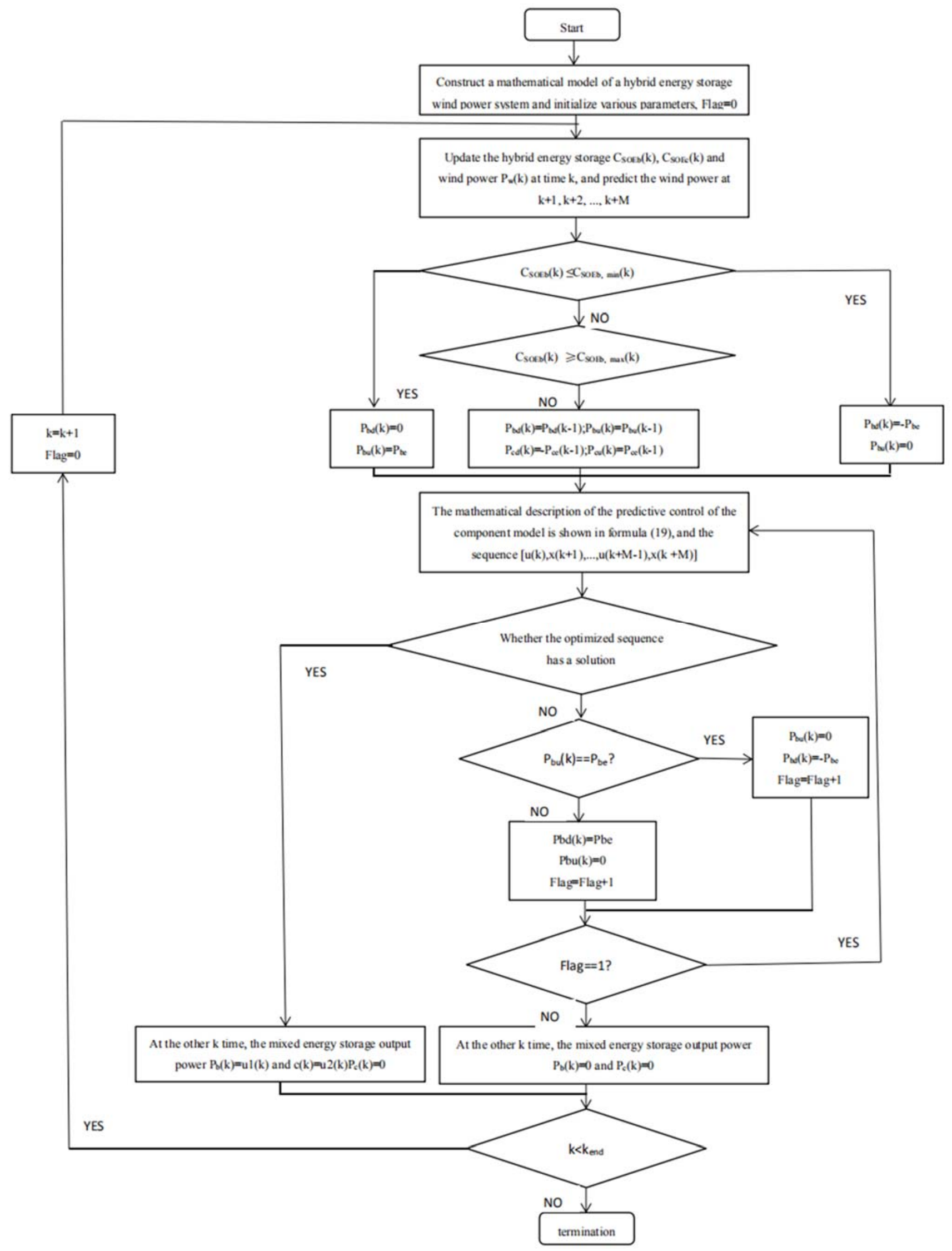

Fig.2 Model predictive control flow chart of a hybrid energy storage mode 


\section{Example analysis}

\subsection{Wind power data description and related parameters}

This paper uses a $100 \mathrm{MW}$ wind farm in Liaoning Province as experimental data. A typical day is divided into 1440 sample points per day. The sample interval is $\mathrm{Ts}=1 \mathrm{~min}$. The data curve is as shown in the Fig 3 and the parameters of single and double energy storage system are as shown in Table 1 and Table 2. The grid-connected power fluctuation of the wind-storage system is allowed to be $\delta=5 \mathrm{MW}$, and the time domain length of the model predictive control is $\mathrm{M}=15 \mathrm{~min}$.

Table.1 Single energy storage battery parameters

\begin{tabular}{cc}
\hline Parameter & Value \\
\hline Rated power of energy storage battery $\mathrm{P}_{\mathrm{be}}(\mathrm{MW})$ & 9 \\
Rated capacity of energy storage battery Qbe $(\mathrm{MWh})$ & 1 \\
Energy state upper limit of energy storage battery & 0.8 \\
$\begin{array}{c}\text { CSOE,max } \\
\text { Energy state upper limit of energy storage battery } \\
\text { CSOE,min }\end{array}$ & 0.2 \\
Initial state of energy storage battery $C_{\mathrm{SOE}, \mathrm{b}}(0)$ & 0.5 \\
\hline
\end{tabular}

Table.2 Hybrid energy storage system parameters

\begin{tabular}{cc}
\hline parameter & Value \\
\hline Rated power of battery $P_{\text {be }}(\mathrm{MW})$ & 3 \\
Rated capacity of battery $Q_{\mathrm{be}}(\mathrm{MWh})$ & 0.9 \\
Battery energy state upper limit $C_{\mathrm{SOEb}, \max }$ & 0.8 \\
Battery energy state upper limit $C_{\mathrm{SOEb}, \min }$ & 0.2 \\
Initial state of battery CsOEb,b $(0)$ & 0.5 \\
Rated power of super capacitor Pce $(\mathrm{MW})$ & 6 \\
Rated capacity of super capacitor Qce $(\mathrm{MWh})$ & 0.1 \\
Super capacitor energy state upper limit CsOEC,max & 0.9 \\
Super capacitor energy state upper limit CsOEC,min & 0.1 \\
Initial state of Super capacitorCsOEc,b $(0)$ & 0.5 \\
\hline
\end{tabular}

In order to compare the effect of smoothing wind power, it can be seen from Tables 1 and 2 that the total rated power and capacity of hybrid energy storage and single energy storage are set as same in this article to eliminate the impact of different energy storage power and capacity. Batteries are used as energy type energy storage and super capacitors are used as power-type energy storage. The power of batteries and super capacitors in hybrid energy storage is distributed at a ratio of $1: 2$, and the capacity is allocated at a ratio of 9 : 1.

\subsection{Power fluctuation smoothing results}

Based on the above parameter settings (as shown in Tables 1 and 2) and related indicators (as shown in formulas (4) to (11)), the smoothing effect of wind power fluctuations is compared. The grid-connected power curve of wind-storage system is shown in Fig 3.
The grid-connected power fluctuations are shown in Fig 4 , and the output power and SOE change curves of single and hybrid energy storage are shown in Fig 5 and 6. The specific index results are shown in Table 3.

Table.3 Evaluation index comparison

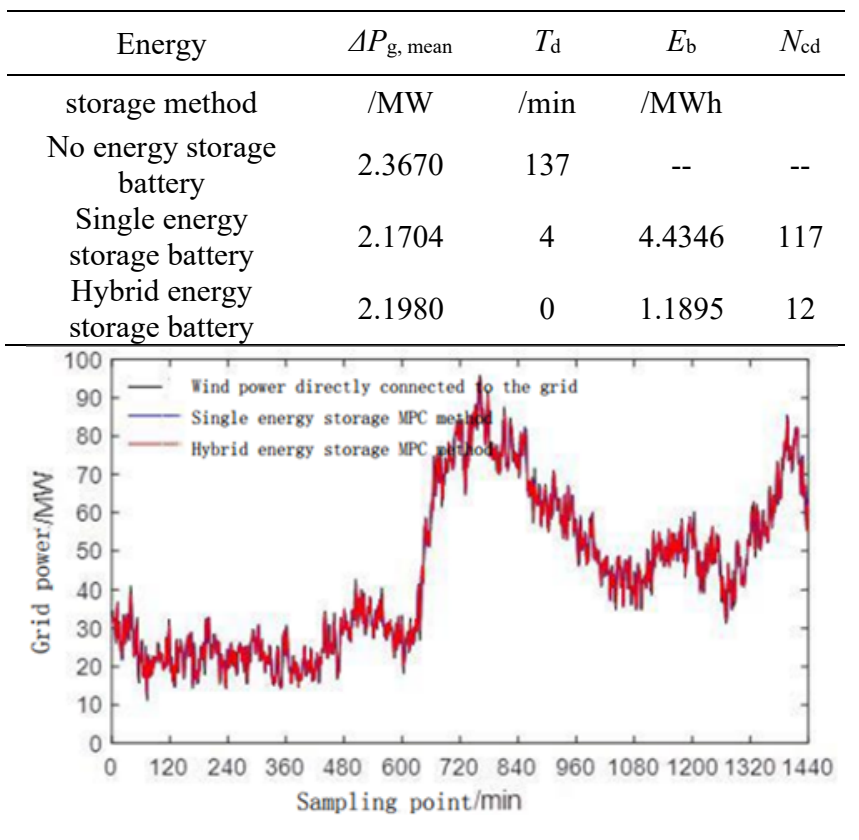

Global map

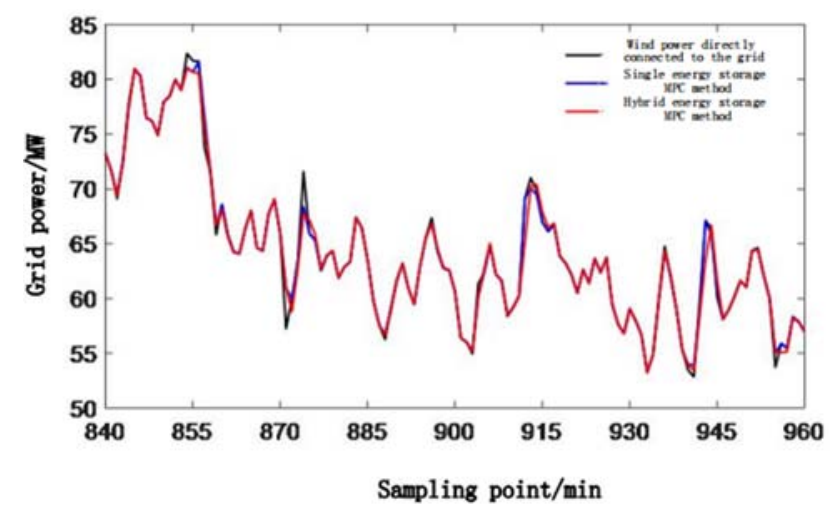

(b) Partial map

Fig.3 Comparison of grid-connected power with different energy storage model using model predictive control

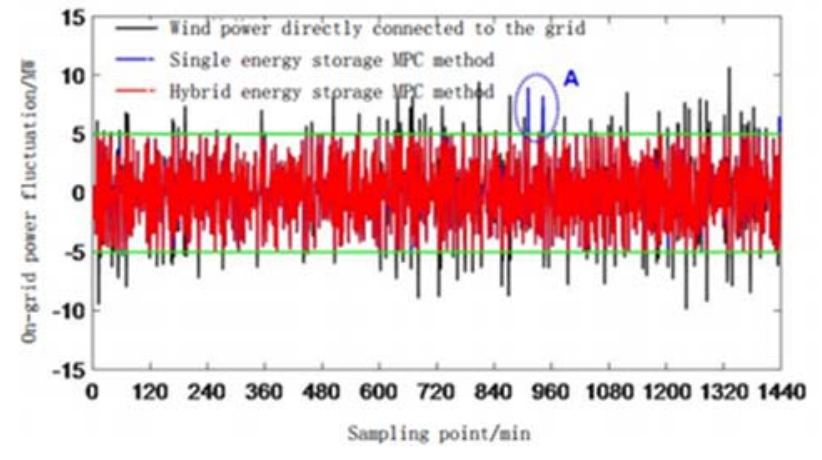

(a) Global map 


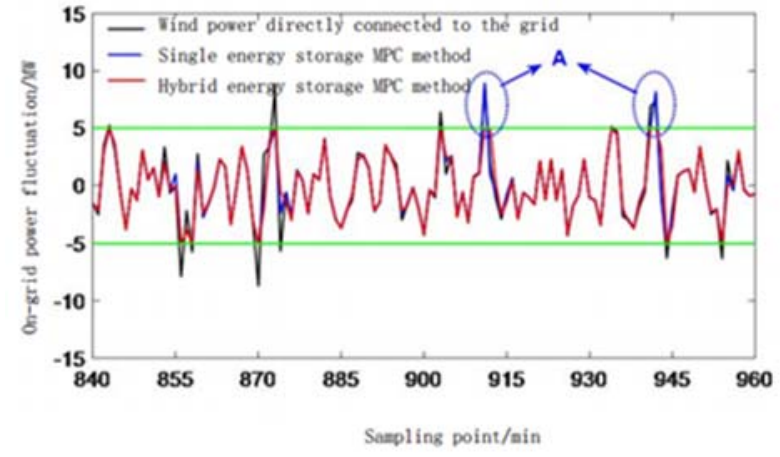

(b) Partial map

Fig.4 Comparison of grid-connected power fluctuations with different energy storage model using model prediction control

According to the grid-connected power curves and indicators in Table 3, Fig 3, and Fig 4, it can be seen that: 1) Before the wind power is smoothed, the maximum fluctuation of the wind power in $1 \mathrm{~min}$ is $10.62 \mathrm{MW}$, which includes 137 minutes that does not meet the grid-connected power fluctuation requirements. 2) Under the model predictive control method of a single energy storage battery system with rated power of 9MW and capacity of $1 \mathrm{MWh}$, the maximum fluctuation is $8.88 \mathrm{MW}$, and the time required to meet the grid-connected power fluctuation is shortened to 4 minutes, as shown in area A in Fig 4, the reduction is $97.08 \%$. 3) The proposed method is applied to hybrid energy storage systems with the same power and capacity to limit the grid-connected power fluctuation to $5 \mathrm{MW}$, which fully meets the grid-connected power fluctuation requirements. This explains the proposed hybrid energy storage control method is more superior.
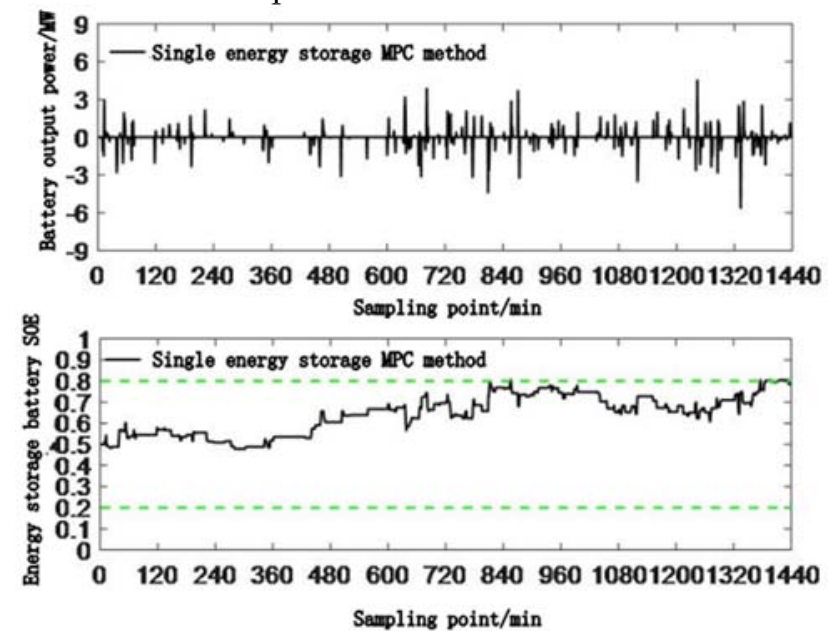

Fig.5 Control process diagram of wind power fluctuation with single battery energy storage
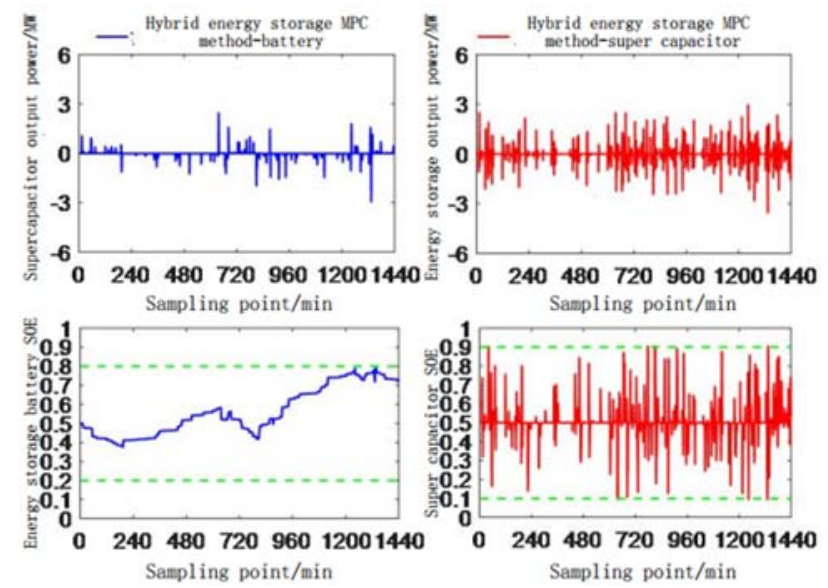

Fig.6 Control process diagram of wind power fluctuation with hybrid energy storage

Combining Table 3, Fig 5 and Fige 6 with the energy storage output power and SOE curves, it can be seen that: 1) Single energy storage battery is frequently switched between charge and discharge, up to 117 times; 2) The super capacitor in hybrid energy storage system undertakes the large value and high frequency power fluctuations, and the energy state approaches the maximum charge and discharge capacity value $\left(\mathrm{C}_{\mathrm{SOE}}\right.$,mid $=0.5$ ). Energy storage batteries bear small amplitude and low frequency power fluctuations. The number of charge and discharge switching is only 12 times, compared to single energy storage battery the time is reduced by $89.74 \%$ The energy storage battery charge and discharge energy is reduced by $73.18 \%$, which means that the hybrid energy storage model predictive control strategy proposed in this paper significantly reduces the charge and discharge switching number and energy of of the energy storage battery, ensuring the energy storage operation life..

\subsection{Economic analysis}

Based on the above wind power smoothing results, this paper analyzes the advantages of the proposed hybrid energy storage model predictive control method from an economic perspective. The super capacitor has a high cycle life. This article does not consider the impact of the super capacitor's charge and discharge times. For energy storage batteries, the depth of charge and discharge and the number of charge and discharge cycles are the key factors affecting their cycle life. According to the data on the correspondence between the discharge depth and cycle life of a certain type of battery in Table 4 [14-15], a binomial exponential function is used to characterize the relationship between the battery cycle life and the discharge depth, as shown in formula (20).

Define the life loss of the battery during the entire working cycle, as shown in formula (21).

$$
N_{e}\left(D_{\mathrm{oD}}\right)=23970 \times e^{-43.06 D_{\mathrm{oD}}}+4533 \times e^{-2.64 D_{\mathrm{oD}}}
$$




$$
N_{\mathrm{a}}=\sum_{i=1}^{N} \frac{1}{N_{e}\left(D_{\mathrm{oD} i}\right)}
$$

$\mathrm{N}_{\mathrm{e}}\left(\mathrm{D}_{\mathrm{OD}}\right)$ is the corresponding cycle life when the discharge depth is $\mathrm{D}_{\mathrm{OD}}$. When $\mathrm{N}_{\mathrm{a}}=1$, the battery life of this batch is considered to be exhausted and the energy storage battery needs to be updated.

Table.4 Relationship between the depth of discharge and cycle life for a type of lead-acid battery

\begin{tabular}{cc|cc}
\hline $\begin{array}{c}\text { Discharge } \\
\text { depth }\end{array}$ & Cycle life & $\begin{array}{c}\text { Discharge } \\
\text { depth }\end{array}$ & Cycle life \\
\hline 0.01 & 20000 & 0.6 & 900 \\
0.1 & 3800 & 0.7 & 750 \\
0.2 & 2850 & 0.8 & 650 \\
0.3 & 2050 & 0.9 & 600 \\
0.4 & 1300 & 1.0 & 550 \\
0.5 & 1050 & & \\
\hline
\end{tabular}

The mixed energy storage cost includes initial cost, replacement cost, and operation and maintenance cost. The calculation formula is as follows:

1) Initial cost:

$$
I_{\mathrm{es}}=c_{\mathrm{bp}} \times P_{\mathrm{be}}+c_{\mathrm{bQ}} \times Q_{\mathrm{be}}+c_{\mathrm{cp}} \times P_{\mathrm{ce}}+c_{\mathrm{cQ}} \times Q_{\mathrm{ce}}
$$

Among them, $\mathrm{c}_{\mathrm{bp}}, \mathrm{c}_{\mathrm{bQ}}, \mathrm{P}_{\mathrm{be}}$ and $\mathrm{Q}_{\mathrm{be}}$ are power unit price, capacity unit price, rated power and capacity of the energy storage battery. $\mathrm{c}_{\mathrm{cp}}, \mathrm{c}_{\mathrm{CQ}}, \mathrm{P}_{\mathrm{ce}}$ and $\mathrm{Q}_{\mathrm{ce}}$ are super capacitor power unit price, capacity unit price, rated power and capacity.

2) Replacement cost:

$$
R_{\mathrm{es}}=n\left(c_{\mathrm{bp}} \times P_{\mathrm{be}}+c_{\mathrm{bQ}} \times Q_{\mathrm{be}}\right)
$$

where $\mathrm{n}$ is the number of replacements of the energy storage battery.

3) Operation and maintenance costs:

$$
O_{\mathrm{es}}=T\left(c_{\mathrm{bm}} \times Q_{\mathrm{be}}+c_{\mathrm{cm}} \times Q_{\mathrm{ce}}\right)
$$

$\mathrm{T}$ is the service time of the energy storage battery, $\mathrm{c}_{\mathrm{bm}}$ and $\mathrm{c}_{\mathrm{cm}}$ are the maintenance unit prices of the energy storage battery and the super capacitor, then the total cost of hybrid energy storage is Ces = Ies + Res + Oes.

According to the above analysis principles and the unit cost of energy storage batteries and super capacitors in Table 5, the rain current counting method [14-15] is used to calculate the energy storage battery losses. The single and mixed energy storage costs are determined, as shown in Table 6.It can be seen from the comparison that the hybrid energy storage battery can save about $70.25 \%$ of the cost compared to the single type of energy storage. Therefore, the hybrid energy storage method for smoothing wind power fluctuations proposed in this paper can effectively extend the service life of energy storage batteries, reduce replacement costs, improve the economics of energy storage applications, and has better advantages.

Table.5 Energy storage price per unit

\begin{tabular}{cccc}
\hline $\begin{array}{c}\text { Energy } \\
\text { storage } \\
\text { type }\end{array}$ & $\begin{array}{c}\text { Unit price } \\
\text { of power } \\
\text { (yuan/W) }\end{array}$ & $\begin{array}{c}\text { Unit price } \\
\text { of capacity } \\
(\text { yuan/W•h) }\end{array}$ & $\begin{array}{c}\text { Maintenance } \\
\text { unit price } \\
(\text { yuan } / \mathrm{W} \bullet \mathrm{h})\end{array}$ \\
\hline $\begin{array}{c}\text { Battery } \\
\text { Super } \\
\text { capacitor }\end{array}$ & 1.5 & 1 & 0.5 \\
\hline
\end{tabular}

Table.6 Comparison of energy storage cost Ces

\begin{tabular}{cccc}
\hline & Single & Hybrid & \\
Total & energy & energy & Cost \\
capacity & storage & storage & reduction \\
MWh & Ces/ten & Ces/ten & rate \\
& thousand & thousand & $\%$ \\
& yuan & yuan & \\
\hline 1 & 6959.3 & 2070.4 & 70.25 \\
\hline
\end{tabular}

\subsection{Parameter impact analysis}

In order to further analyze the wind power smoothing effect of the proposed model predictive control method, this paper analyzes the grid-connected wind power fluctuation index $\delta$, the total rated power and total capacity of the energy storage system. The battery and super capacitor have a power ratio of 1: 2 and a capacity ratio of 9: 1 .

1) Allowable grid-connected power fluctuations:

Let the total rated power of the hybrid energy storage be $9 \mathrm{MW}$ and the capacity be $1 \mathrm{MWh}$, change the allowable grid-connected power fluctuation requirement $\delta$, and compare the smoothing indicators of the predictive control of the single and hybrid energy storage models, as shown in Fig 7. 

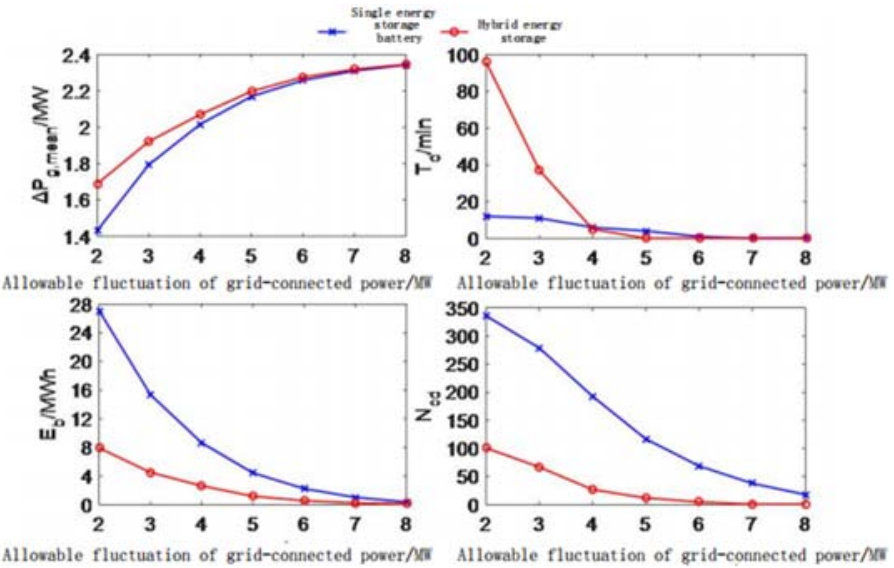

Fig.7 Evaluation index curves under different grid-connected power fluctuation requirements $\delta$

As can be seen from Fig 7, 1, As the allowable range of grid-connected power increases, the control effect of both single-storage battery and hybrid energy storage becomes better. 2) In terms of the average absolute value of grid-connected power fluctuations $\Delta \mathrm{P}_{\mathrm{g}}$, mean, single energy storage is similar to the smoothing effect of hybrid energy storage. 3) When the grid-connected power allowable range is strict, the $T_{d}$ of hybrid energy storage is large. The reason is that the rated power of battery in hybrid energy storage is too low to suppress power fluctuations. The allowable range is widened, and the $T_{d}$ value is rapidly decreased. 4) In the battery charge and discharge energy $E_{b}$ and the number of switching times $\mathrm{N}_{\mathrm{cd}}$, the hybrid energy storage method proposed in this paper is much better than the single energy storage battery.

2) Total power of energy storage:

Let the total hybrid energy storage capacity be $1 \mathrm{MWh}$, and allow the grid-connected power fluctuation requirement to be $\delta=5 \mathrm{MW}$. Compare the smoothing indicators under different total energy storage power, as shown in Fig 8.

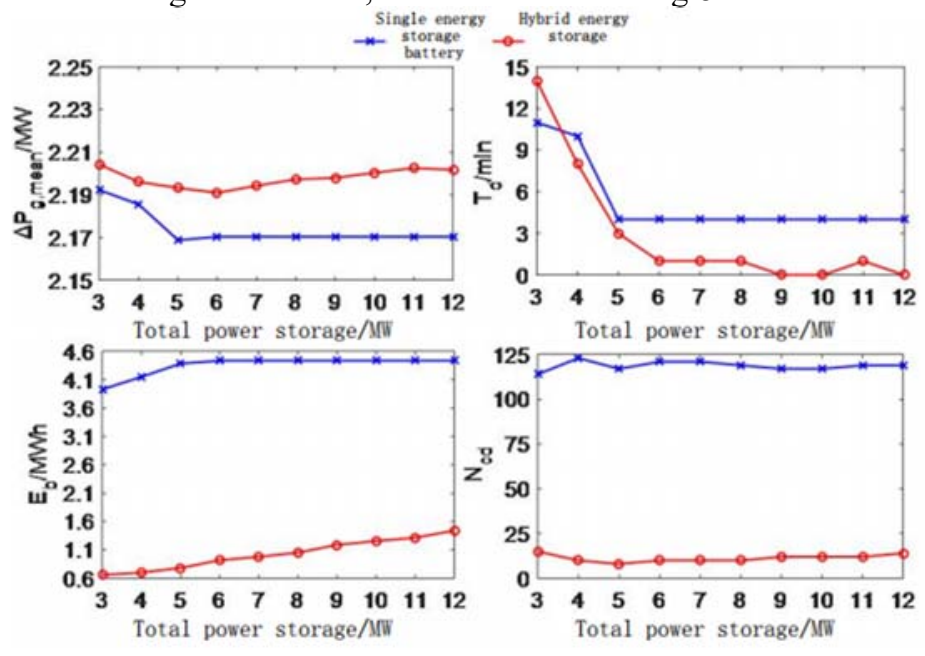

Fig.8 Evaluation index curves under different energy storage rated power

As can be seen from Figure 8,1) When the allowable fluctuation range of the grid-connected power is determined, after the total rated power of the single energy storage and the hybrid energy storage increases to a certain value, the evaluation indexes are basically unchanged. Combined with the conclusion of Figure 7, it is shown that the rated energy storage power is related to the fluctuation range of grid-connected power operation, and its value has limited ability to improve the smoothing effect. 2) As can be seen from various indicators, the model predictive control of hybrid energy storage proposed in this paper takes into account the requirements for smooth power fluctuations of the power grid and protection of energy storage batteries, and has a better control effect.

3) Total capacity of energy storage:

Let the total power of the hybrid energy storage be $9 \mathrm{MW}$, and the grid-connected fluctuate power to $\delta=$ $5 \mathrm{MW}$. Compare the smoothing indicators under different total energy storage capacities, as shown in Fig 9 


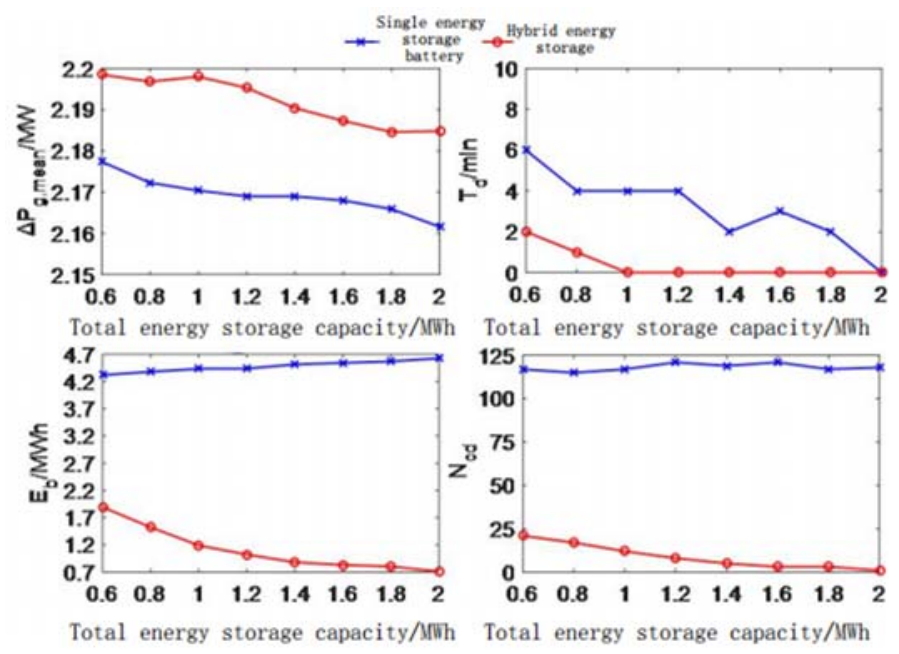

Fig.9 Evaluation index curves under different energy storage capacities

It can be seen from Fig 9 that under the premise of determining the power and grid-connected power fluctuation requirements, as the total capacity of the energy storage system increases, 1) the grid-connected power fluctuation decreases, and the time that does not meeting the grid-connected power fluctuation significantly decreases. 2) In hybrid energy storage, the output energy of the energy storage battery and the number of charge-discharge switching times continue to decrease. 3) The predictive control method of the hybrid energy storage model proposed in this paper has significant advantages.

\section{Conclusion}

This paper considers two aspects of grid-connected wind power fluctuations and energy storage battery life protection, and proposes a method for smoothing wind power fluctuations using hybrid energy storage. First, a model predictive control strategy for hybrid energy storage is established, which increases the capacity of the energy storage battery to cope with future wind power fluctuations and reduces the time that the energy storage battery enter the limit range. Then, the composite optimized goals of the energy storage battery, the minimum output of the super capacitor, and the maximum charge and discharge capacity of the super capacitor are designed, which improves the smoothingcapacity of the super capacitor and reduces the charge and discharge energy of the energy storage battery. Moreover, predicting the output range of the energy storage battery during the optimization process effectively reduces the number of switching times of the energy storage battery. On the basis of meeting the requirements for smooth wind power fluctuations, the cycle life of the energy storage battery is reasonably protected and the replacement cost of the energy storage battery is reduced. It is conducive to the economic operation of energy storage and smooth wind power fluctuation.

\section{Acknowledgement}

Supported by Beijing Urban Governance Research Project "Mobile Power to Improve Urban Emergency Management Capability" (20XN239)

\section{Note brief}

Li jianlin, born in 1976, $\mathrm{PhD}$, professor Major research interests include grid-connected inverters control technology, the impact of distributed generation on power quality and micro-grid control technology. E-mail:dkylj1@163.com (Corresponding author)

\section{References}

1. He Shi-en, Zheng Wei, Zhi Yong, et al. Power quality issues of large-scale cluster wind power integration[J].Power System Protection and Control, 2013, 41(2):39-44.

2. Zhang Liying, Ye Tinglu, Xin Yaozhong, et al. Problems and measures of power grid accommodating large scale wind power[J]. Proceedings of the CSEE, 2010, 30(25):1-9(in Chinese)

3. Yuan Xiaoming, Cheng Shijie, Wen Jinyu. Prospects analysis of energy storage application in grid integration of large-scale wind power[J]. Automation of electric power systems, 2013, 37(1):14-18.

4. JANNATI M, HOSSEINIAN S H, VAHIDI B, et al. ADALINE (ADAptive Linear NEuron)-based coordinated control for wind power fluctuations smoothing with reduced BESS (battery energy storage system) capacity[J]. Energy, 2016, 101: 1-8..

5. Zhang Ye, Guo Li, Jia Hongjie, et al. A new battery energy storage system control method based on SOC and variable filter time constant $[\mathrm{J}]$. Automation of Electric Power Systems, 2012, 36(6): 34-38..

6. Shi Linjun, Zhou Jiajia, Wen Rongchao, et al. Power smoothing control of wind power based on 
combination of empirical mode decomposition and wavelet analysis $[\mathrm{J}]$. Power System Protection and Control, 2016, 44(24) :9-16

7. Wang Xiaodong, Zhang Lei, Yao Xingjia, et al.Afuzzy adaptive Kalman filter based power control strategy of energy storage system for wind farm[J].Power System Technology, 2014, 38 (6) :1465-1470.

8. Yang Xiyun, Cao Chao, Li Xiangjun, et al.Control strategy of smoothing wind power output using battery energy storage system based on fuzzy empirical mode decomposition[J].Electric Power Construction, 2016, 37 (8):134-140.

9. Liu Liyang, Wu Junji, Meng Shaoliang. A Rolling Dispatch Model for Wind Power Integrated

10. Khalid M, Savkin A V. A model predictive control approach to the problem of wind power smoothing with controlled battery storage[J]. Renewable Energy, 2010, 35(7): 1520-1526.

11. Liu Yingming, Wang Wei, Wang Xiaodong, et al. A Fuzzy Control Strategy Combined With Wind Power Prediction and Energy Storage SOE for Smoothing Wind Power Output[J]. Power System Technology, 2019,43(7):2535-2543

12. Guo Ziqiang. Economical Cycle Life for Lead-acid Batteries $[\mathrm{J}]$. Marine Electric \& Electronic Engineering, 2014, 34(2):13-16.

13. Gao Fei, Yang Kai, Hui dong, et al. Cycle-life Energy Analysis of LiFePO4 Batteries for Energy Storage[J]. Proceedings of the CSEE, 2013, 33(5):41-45.

14. Han Xiaojuan, Chen Cheng, Ji Tianming, et al. Capacity Optimal Modeling of Hybrid Energy Storage Systems Considering Battery Life $[\mathrm{J}]$. Proceedings of the CSEE, 2013, 33(34):91-97.

15. Bin Yang, Yu Jingmei, et al. A Real-time Rain Flow Algorithm and Its Application to State of Health Modeling for LiCoO2 Lithium-ion Batteries[J]. Proceedings of the CSEE, 2017,37(12):269-277+334.

16. Zhang Xinsong, Gu Juping, Yuan Yue, et al.Strategy of smoothing wind power fluctuation based on battery energy storage system[J].Proceedings of the CSEE, 2014, 34 (28) :4752-4760.

17. Zhang Zhuyao, Guo Xiaoli, Zhang Xinsong, et al. Strategy of smoothing wind power fluctuation based on storage battery[J].Power System Protection and Control, 2017,45(3): 62-68.

18. Sun Yushu, Zhang Guowei, Tang Xisheng, et a1. Research on MPC and daul energy storage control strategies with wind power fluctuation mitigation[J].Transactions of China Electrotechnical Society, 2019,34(3): 571-578..

19. Jiang Ping. Xiong Huachuan. A control scheme design for smoothing wind power fluctuation with hybrid energy storage system[J].Automation of electric power systems, 2013, 37(1):122-127.

20. Zhang Qing, Li Xinran, Yang Ming, et al. Capacity Determination of Hybrid Energy Storage System for Smoothing Wind Power Fluctuations with Maximum Net Benefit[J]. Transactions of China Electrotechnical Society, 2016, 31(14): 40-48.

21. Fu Juxia, Chen Jie, Teng Yangxin, et al. Energy Management Coordination Control Strategy for Wind
Power Hybrid Energy Storage System Based on EEMD $[J]$. Transactions of China Electrotechnical Society, 2019, 34(10): 2038-2046.

22. Li Yanan, Wang Qian, Song Wenfeng, et al. Variational mode decomposition and fuzzy control strategy of hybrid energy storage for smoothing wind power outputs $[\mathrm{J}]$. Power System Protection and Control, 2019, 47(07):65-72.

23. Sun Yushu, Tang Xisheng, Sun Xiaozhe, Jia Dongqiang, Wang Ping, Zhang Guowei. Research on Multi-type Energy Storage Coordination Control Strategy Based on MPC-HHT[J]. Proceedings of the CSEE, 2018,38(09):2580-2588+2826. 